\title{
DESIGN AND ANALYSIS OF PUNCHING DIE
}

\author{
A.K.Kumaresh ${ }^{1}$, B.Balaji ${ }^{2}$, M. Raj Kumar ${ }^{3}$ \\ ${ }^{1}$ M.E. (student), Engineering Design, Sri Shakthi Institute of Engineering and Technology, Coimbatore - 62, \\ Tamilnadu, India \\ ${ }^{2}$ Assistant professor, Mechanical Department, Sri Shakthi Institute of Engineering and Technology, Coimbatore - 62, \\ Tamilnadu, India. \\ ${ }^{3}$ Professor, Mechanical Department, Sri Shakthi Institute of Engineering and Technology, Coimbatore - 62, \\ Tamilnadu, India.
}

\begin{abstract}
The sheet metal working processes is predominantly used in various aspects not only for industrial purposes and also utilized for commercial purposes as well. For that many people are engaged in developing the trends by their innovative ideas. Especially in die design, they made different die set for different functionality such as compound die, progressive die, steel-rule die, modular die, sectional die, transfer die, etc. These die are functioned with their own perspective criteria. Due to this, peoples are in Micro small medium scale industries suffered from investing more in single die set. They are unable to overcome the profit with better margins and some are in dead weight which is very difficult to handle by a single person. The main aim of this paper is to design a die with interchangeable die and punches and reduce the weight of the material by means of changing the materials of die sets. This paper mainly focuses on different operations done in single die set with various stations just like a progressive die. But the difference is mode of operation - Progressive die can perform a sequence of operation at a single stroke of press, here this die can perform an individual operation in each station on the die set at a single stroke of press. This should constantly eliminating the loss in production time and reduces the man power from loading and unloading the sheets. The parts of the die sets, punch and die are designed in the solid works and assembled with the mounting hardware. The Finite element analysis of each part of the die sets are done with the simulationxpress tool.
\end{abstract}

Keywords: Die, LM6 Alloy, Plain Carbon Steel, Mounting Hardware, Simulationxpress.

\section{INTRODUCTION}

Now a days, manufacturing sectors replaced most expensive and casted components by means of sheet metal parts. From this phenomenon the cost of the products and the weight of the components are reduced as much as possible. The production rate of each part is increased with the few set of die. These must come up with the leads to drive the new technology with various aspects. Here, the sheet metal working processes come into play as a metal forming processes. It may also called as press working processes. With the help up of Punch and die set, the sheet metal may deforms into various shapes by the theory of sheet metal behavior described by Ivana Suchy [1].

\subsection{Types of Dies}

The theory of sheet metal behavior kept as a backbone for the development of various kinds of dies which are differentiable through their function. In some of the dies, the sheet metal should be cut off from the strip and the remaining part is removed as a scrap. In some other dies, the complete part is finished within the single station. According to their construction and functions the die is divided into following groups [1].

\subsection{Compound Dies}

The die which undergone to more than two cutting operations like blanking and perforating etc. can be performed continuously in a single stroke. In compound die, the upper punch is connected to the ram comes in constant with metal and pierces the hold. This punch is moving downward, the springs keep on compressing and after certain limit the lower punch moves upward and blanks the outer portion. Here, the whole operation is performed at single station, it produces accurate result but the die design is complicated.

\subsection{Combination Dies}

The die which undergone the cutting and forming operations are combined and carried out in a single operation. First blank is prepared in the die and then it is held by pressure pads and drawn. All this is achieved entirely within the die assembly by use of cam actuated punch and die members or by designing the die for use on a double action press which has two independent rams or slides on moving inside another.

\subsection{Progressive Dies}

In progressive dies, the work pieces move from the first station to successive which carries variable operations, to be performed in individual station. Each stations works in series manner and the work piece is placed in stock till at the end of station which cuts off finished piece. End of the each stroke, the stock is moving towards by one station and the complete work piece is constructed in a single stroke of ram. 
It can be designed for complicated operations of bending, forming etc. In these dies, indexing at every station is very important and therefore accuracy is not much. However, it is simple in design.

\section{DIE CONSTRUCTION}

The die set is the primary portion of every die construction. It made up of upper die and lower die both are machined in parallel in size. The portion of the die is provided with the shank which is used to clamp in the ram of the press. Both the upper die and lower die are aligned with the guide pins. They are firmly attached to the stripper and the upper die is equipped with the bushings into which these pins slip-fit.

The die blocks are mounted in the lower die in which they are attached through the die buttons. The punch plate is mounted on the upper shoe in which same manner as the die block. It holds all the punches which are perforated the sheet with the help of die at the bottom. While doing the punching operations, the punches can be prevented from the cracks by the spring loaded stripper plate. The stripper plate is held in the top plate with an offset location of forces of springs by means of guide pins.

This die set is the combination of two die set. The upper die set is rectangular in shape with four post die set. The lower die set is rectangular in shape with open die set which is used for simple parts in larger quantities.

\subsection{Materials Used In Die}

The die set is made up of Aluminium - Silicon alloy by replacing the tool steel material which enhance the high ductility and high hardness level. This material is suggested for light weight of the die and it tends to deforms while the thrust force is applied, regain its original shape. However it is good corrosion resistance. It is able to sustain up to $10 \mathrm{bar}$ pressure which is applied by the hydraulic press [2].

Table - 1: Die components materials

\begin{tabular}{|l|l|l|l|l|}
\hline $\begin{array}{l}\text { Sl. } \\
\text { No }\end{array}$ & Die parts & $\begin{array}{l}\text { Material } \\
\text { used }\end{array}$ & $\begin{array}{l}\text { Young's } \\
\text { modulus } \\
\left(\mathrm{N} / \mathrm{mm}^{2}\right)\end{array}$ & $\begin{array}{l}\text { Density } \\
\mathrm{g} / \mathrm{cm}^{3}\end{array}$ \\
\hline 1 & Punches & $14 \mathrm{C6}$ & $2.1 \times 10^{5}$ & \\
\hline 2 & Die & $14 \mathrm{C6}$ & $2.1 \times 10^{5}$ & \\
\hline 3 & $\begin{array}{l}\text { Top \& } \\
\text { bottom plate }\end{array}$ & $\begin{array}{l}\text { LM6 } \\
\text { Alloy }\end{array}$ & $72 \times 10^{3}$ & 2.65 \\
\hline 4 & $\begin{array}{l}\text { Guide pin \& } \\
\text { bushes }\end{array}$ & $\begin{array}{l}\text { LM6 } \\
\text { Alloy }\end{array}$ & $72 \times 10^{3}$ & 2.65 \\
\hline 5 & Shank & $\begin{array}{l}\text { LM6 } \\
\text { Alloy }\end{array}$ & $72 \times 10^{3}$ & 2.65 \\
\hline 6 & $\begin{array}{l}\text { Guide } \\
\text { supporter }\end{array}$ & $\begin{array}{l}\text { LM6 } \\
\text { Alloy }\end{array}$ & $72 \times 10^{3}$ & 2.65 \\
\hline 7 & Punch plate & $\begin{array}{l}\text { LM6 } \\
\text { Alloy }\end{array}$ & $72 \times 10^{3}$ & 2.65 \\
\hline
\end{tabular}

\subsection{Chemical Composition of LM6 Alloy}

Table - 2: Ingot compositions

\begin{tabular}{|l|l|}
\hline Materials & In percentage \\
\hline $\mathrm{Cu}$ & $0.1 \%$ \\
\hline $\mathrm{Mg}$ & $0.1 \%$ \\
\hline $\mathrm{Si}$ & $10 \%-13 \%$ \\
\hline $\mathrm{Fe}$ & $0.6 \%$ \\
\hline $\mathrm{Mn}$ & $0.5 \%$ \\
\hline $\mathrm{Ni}$ & $0.1 \%$ \\
\hline $\mathrm{Zn}$ & $0.1 \%$ \\
\hline $\mathrm{Pb}$ & $0.1 \%$ \\
\hline $\mathrm{Sn}$ & $0.05 \%$ \\
\hline $\mathrm{Al}$ & Rest \\
\hline
\end{tabular}

Since, the percentages in the table are in pre-casting compositions. It may slightly vary the compositions while casting processes undergone [3].

\subsection{Chemical Composition Of 14C6 Alloy}

Table - 3: Case hardened steel

\begin{tabular}{|l|l|}
\hline Materials & In percentage \\
\hline $\mathrm{C}$ & $0.1 \%-0.18 \%$ \\
\hline $\mathrm{Si}$ & $0.05 \%-0.35 \%$ \\
\hline $\mathrm{Mn}$ & $0.40 \%-0.70 \%$ \\
\hline $\mathrm{P}$ & $0.035 \%$ \\
\hline $\mathrm{S}$ & $0.035 \%$ \\
\hline
\end{tabular}

The above chemical composition of case hardened alloy steels for cold heading and cold extruding, conforming to IS 11169(1) - 1984 [4].

\subsection{Die - Set Structure}

The die set designed as per design data [5]. The top plate is designed as a pillar die set with a rectangular working space. The overall dimension of die set is 315 X $250 \mathrm{~mm}$. And the working area of the die is $200 \mathrm{X} 150 \mathrm{~mm}$. The shank is fixed at the centre of the plate which is the centre of gravity of the whole region. The guide bushing of the top plate is aligned at the four corners of the rectangle and it is equidistance to all directions. The punches are aligned in a straight line at the centre axis of the plate. The punches such as piercing, blanking, bending is fixed in the punch plate through mounting hardware. 


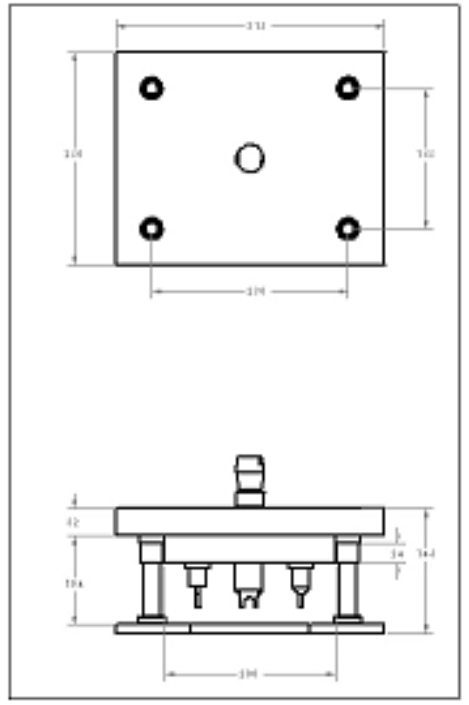

Fig - 1: Top plate assembly

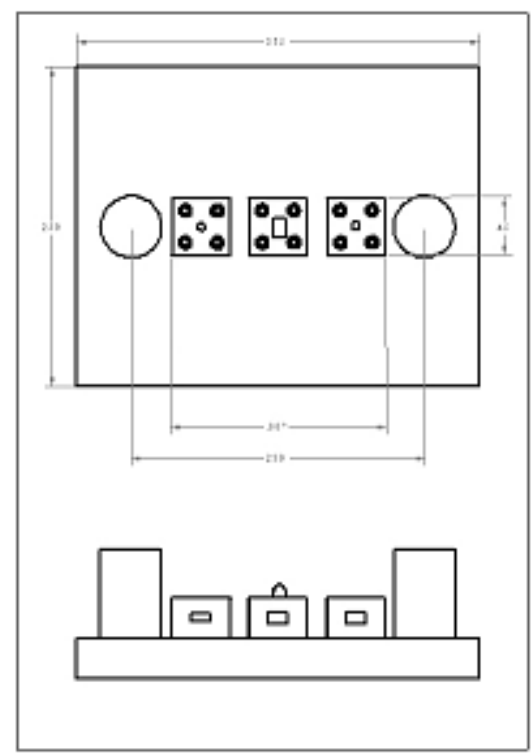

Fig - 2: Bottom plate assembly

The bottom plate consists of two guide supporter mounted on either side of the plate, which is used to safeguard the die from the stripper plate. This should enable the working space in the bottom plate. The different stations of die are placed in it such as piercing, bending, blanking which are aligned in series manner.

\subsection{Clearance And Tool Life}

Clearance $=\mathrm{D}-\mathrm{d}$

Where, $\mathrm{D}=$ Diameter of the die

$\mathrm{d}=$ Diameter of the punch

In blanking, die governs the size of the cut, the punch dimensions are to be reduced by the amount determined by the clearance. In piercing, the punch governs the size of the cut. The die dimension is increased by the required clearance [5].

The clearance between punch and die are depends on the material properties which are gone to be sheared. For a materials which are ductile in nature, has a less clearance value and for soft material will have a large clearance value. Apart from this, Excess die clearance will cause burr formation in the sheared material. By avoiding that, the punch and die should have a limited clearance value and this leads to reduction in tool life. For instance, increase of tool life by means of doubling the die clearances. Hence, whenever the accuracy of blanking dimension is not important. It is advised to keep the excess die clearances and remove the tensile burr manually. For a mild sheet metal, the clearance should be recommended as $2.5 \%$ to $5.0 \%$ of its thickness [6].

The recommended die clearance $=3.5 / 100 * 2 \mathrm{~mm}$

$$
=0.070 \mathrm{~mm}
$$

The die bore $=$ Punch diameter $+2($ Die clearance $)$

\subsection{Calculation Of Force}

\section{Cutting force}

The cutting force applied in the punch to perform a punching operations such as piercing and blanking in the stock material can be calculated by the actual shear strength and the area of the material using formulae [6].

$\mathrm{F}=f_{s} \mathrm{X} L_{g} \mathrm{Xt}$

Cutting force parameters are

$f_{g}=$ Cutting strength of the sheet in N/mm²

$L_{s}=$ Cutting length in $\mathrm{mm}$

$\mathrm{t}=$ Thickness of the sheet in $\mathrm{mm}$

Cutting force at station one $\left(F_{1}\right)$

$$
\begin{aligned}
F_{1} & =f_{s} \times L_{g} \times \mathrm{t} \\
& =241 \times 45 \times 2 \\
& =21,690 \mathrm{~N}
\end{aligned}
$$

Cutting force at station three $\left(F_{a}\right)$

$$
\begin{aligned}
F_{a} & =f_{g} \times L_{g} \times \mathrm{t} \\
& =241 \times 45 \times 2 \\
& =21,690 \mathrm{~N}
\end{aligned}
$$

The total cutting force is the sum of the cutting force on two stations of the punching die.

Total cutting force, $\mathrm{F}=F_{1}+F_{\mathrm{a}}$

$$
=43,380 \mathrm{~N}
$$

\section{Force for bending operation}

The force required for bending operation is measured from the angle and length of the bend, material properties and the direction of bend with respect to grain characteristics [6]. For $\mathrm{U}$ bending force equation as,

$V_{b c}=\frac{2.66 L t^{2} f_{t}}{w}+P_{\text {pad }}$

Bending force parameters are

$$
\begin{aligned}
& V_{b c}=\text { Force for bending } \\
& \mathrm{L}=\text { length of the bend part in } \mathrm{mm} \\
& \mathrm{t}=\text { thickness of the sheet in } \mathrm{mm} \\
& F_{\mathrm{t}}=\text { Tensile strength in } \mathrm{N} / \mathrm{mm}^{2} \\
& \mathrm{w}=\text { width of the material }
\end{aligned}
$$




$$
P_{\text {pad }}=\text { Pressure pad }=\text { one third of bending force }
$$

The required bending force calculation in the second station is

$$
\begin{aligned}
V_{b c} & =\frac{2.66 * 45 * 4 * 241}{45}+769.2 \\
& =3333.44 \mathrm{~N}
\end{aligned}
$$

The F.O.S is increased up to one third of total force. The power required for the press is $46713.44 \mathrm{~N}$ as minimum, which is equal to 5 tons of hydraulic machine.

\section{DESIGN OF DIE PARTS}

\subsection{Die}

The design of die specifically suitable to the bottom plate with respect to the punch. It is made up of plain carbon steel and its hardness is $137 \mathrm{HB}$. The sheet metal is keeps on moving in the transverse direction in three stations. Independently, these stations can perform their operations individually. Once, the metal stamping processes is done the sheet can be moved through time delay sequence and the next stock is move towards the die. The die sections are straight line and angular clearances. The slugs are removed through the opening in the other side of the die.

$T_{d}=\sqrt[3]{F_{\text {gh }}}$

Where,

$$
\begin{aligned}
& T_{d}=\text { thickness of the die plate }[\mathrm{mm}] \\
& F_{\text {gh }}=\text { Shear force [tone] } \\
& \begin{aligned}
T_{D 1} & =\sqrt[3]{2.169} \\
& =12.9 \mathrm{~mm}
\end{aligned}
\end{aligned}
$$

Die thickness $=12.9 \mathrm{~mm}+2 \mathrm{~mm}=15 \mathrm{~mm}$

Therefore, $T_{D 2}=15 \mathrm{~mm}$

$$
\begin{aligned}
T_{D a} & =\sqrt[3]{3.333} \\
& =14.9 \mathrm{~mm}
\end{aligned}
$$

Die thickness $=14.9+2 \mathrm{~mm}=17 \mathrm{~mm}$

\section{Deflection and stress calculation}

Here, the die block is fixed at the bottom plate and thus it is considered as fixed and the beam mechanics come into play. The die block deflection should be less than $0.025 \mathrm{~mm}$ [7].

$\delta=\frac{F L^{\mathrm{a}}}{192 \mathrm{EI}}$

$I=\frac{b h^{a}}{12}$

where, $\mathrm{E}=2.1 \times 10^{5} \mathrm{~N} / \mathrm{mm}^{2}$

$\mathrm{F}=80 \%$ of cutting force act on the longitudinal direction

$\mathrm{E}=$ Young's modulus

I = moment of inertia of the die block

Let us assume that the force is uniformly distributed through the die block.

$$
\begin{aligned}
\mathrm{F} & =0.8 \times 21,690 \mathrm{~N} \\
& =17,352 \mathrm{~N}
\end{aligned}
$$

$\mathrm{L}=$ Screw distance in die block $=25 \mathrm{~mm}$

$\mathrm{b}=$ width of the die block $=45 \mathrm{~mm}$

$\mathrm{h}=$ height of the die block $=32 \mathrm{~mm}$

$$
\begin{aligned}
\mathrm{I}=122,880 \mathrm{~mm}^{4} \\
\delta=0.0016 \mathrm{~mm} \\
\sigma=\mathrm{F} / \mathrm{A} \\
=8.56 \mathrm{~N} / \mathrm{mm}^{2}
\end{aligned}
$$

The stress applied to the die block is $8.56 \mathrm{~N} / \mathrm{mm}^{2}$ which is much less than $500 \mathrm{~N} / \mathrm{mm}^{2}$. Hence the design is safe.

\subsection{Bottom Plate}

The die block and the guide supporter are mounted on the bottom plate which is used to provide an enough space for performing the die operations. The slugs are removed by the suction air in the air vent. It is made up of aluminium silicon alloy (LM6).

$$
\begin{aligned}
T_{b} & =1.5 * T_{d} \\
& =1.5 \times 17=25.5 \mathrm{~mm}
\end{aligned}
$$

\section{Deflection and stress calculation}

It is mounted on the bolster plate in the punching machine which remains gives the cushioning effect to the bottom plate. Since, it is rest in the bolster plate considered as a simply supported beam which is affected by the uniformly distributed load in the system.

$$
\delta=\frac{5 F L^{\mathrm{a}}}{354 E I}
$$

Where, $\mathrm{F}=80 \%$ of the cutting and forming forces

$$
=2666.752 \mathrm{~N}
$$

$\mathrm{L}$ is the beam frame distance $=230 \mathrm{~mm}$

Young's modulus $(\mathrm{E})=72 \times 10^{3} \mathrm{~N} / \mathrm{mm}^{2}$

where, $\mathrm{b}=315 \mathrm{~mm}$ (width of the plate)

$$
\begin{aligned}
\mathrm{h} & =32 \mathrm{~mm} \text { (height of the plate) } \\
\mathrm{I} & =860160 \mathrm{~mm}^{4} \\
\delta & =0.0024 \mathrm{~mm}<0.025 \mathrm{~mm} \\
\sigma & =\mathrm{F} / \mathrm{A} \\
& =0.033 \mathrm{~N} / \mathrm{mm}^{2}
\end{aligned}
$$

The stress applied to the bottom plate is $0.033 \mathrm{~N} / \mathrm{mm}^{2}$ which is much less than $160 \mathrm{~N} / \mathrm{mm}^{2}$. Hence, the design is safe.

\subsection{Top Plate}

The punch assembly and guider assembly along with the stripper plate is hanging in the top plate. Each assembly is assembled in an effective manner through mounting hardware. Here, the top plate is made up of aluminium silicon alloy (LM6).

$$
\begin{aligned}
T_{p} & =1.25 \times T_{d} \\
& =1.25 \times 17 \mathrm{~mm}=21.25 \mathrm{~mm}
\end{aligned}
$$

\subsection{Punch plate}

All the punches are fitted in the punch plate and the punch plate is mounted on the top plate. It is freely moved up and down movement through the guide assembly. It is made up of aluminium silicon alloy (LM6).

$$
\begin{aligned}
T_{\text {ph }} & =0.5 \times T_{d} \\
& =0.5 \times 17 \mathrm{~mm} \\
& =8.5 \mathrm{~mm}
\end{aligned}
$$




\section{Deflection and stress calculation}

Let us assumed to be a SSB beam which are mounted through four corners in the punch plate. It is loaded in the centre of the plate and their deflection should be.

$$
\delta=\frac{F L^{3}}{48 E I}
$$

Where, $\mathrm{F}=80 \%$ of the cutting and forming forces

$$
=2666.752 \mathrm{~N}
$$

$\mathrm{L}$ is the beam frame distance $=150 \mathrm{~mm}$

Young's modulus $(\mathrm{E})=72 \times 10^{3} \mathrm{~N} / \mathrm{mm}^{2}$

where, $\quad b=200 \mathrm{~mm}$ (width of the plate)

$\mathrm{h}=32 \mathrm{~mm}$ (height of the plate)

$\mathrm{I}=860160 \mathrm{~mm}^{4}$

$\delta=0.0004 \mathrm{~mm}<0.025 \mathrm{~mm}$

$\sigma=\mathrm{F} / \mathrm{A}$

$=0.4166 \mathrm{~N} / \mathrm{mm}^{2}$

The stress applied to the punch plate is $0.4166 \mathrm{~N} / \mathrm{mm}^{2}$ which is much less than $160 \mathrm{~N} / \mathrm{mm}^{2}$. Hence, the design is safe.

\subsection{Guide Pins and Bushes}

Guide pins and bushes are made up of aluminium silicon alloy (LM6) which is used to align the punches and the die block. It attached between the top plate and stripper plate.

\section{Buckling for guide pins}

The guide pins materials are made up of LM6 alloy having a tensile strength of $160 \mathrm{~N} / \mathrm{mm}^{2}$ and their young's modulus is $72 \times 10^{3} \mathrm{~N} / \mathrm{mm}^{2}$.

$L_{e}=21$ for one side is fixed and other side is set free.

$1=146 \mathrm{~mm}$

$\mathrm{I}=\frac{\pi D^{4}}{64}$

$\mathrm{D}=22 \mathrm{~mm}$

$\mathrm{I}=1165.68 \mathrm{~mm}^{4}$

$\mathrm{A}=379.94 \mathrm{~mm}^{2}$

$\mathrm{S} . \mathrm{R}=L_{e} / r_{g}$

$r_{g}=\sqrt{\frac{I}{A}}=$ Radius of gyration

$$
=20
$$

S.R $=17.6=$ Slenderness ratio

T.S.R $=\sqrt{\frac{2 \pi^{5} E}{s_{y}}}=$ Transition slenderness ratio

T.S.R $=94.2 \mathrm{~mm}$

Here, the Johnson equation should be applied for critical buckling load. Since, the S.R ratio is lesser than that of T.S.R [7].

$$
\begin{aligned}
& F_{c r i}=A\left(S_{y}-\frac{s_{y^{2}}}{4 \pi^{2} E}\left(\frac{L_{g}}{v_{g}}\right)^{2}\right. \\
& F_{c r i}=2166.6 \mathrm{~N}>\text { critical load }
\end{aligned}
$$

Hence the structure is safe.

Load per pillar $=2166.6 / 4$

$$
=541.65 \mathrm{~N} / \text { pillar }
$$

\subsection{Punch}

The punches are mounted in the punch plate which is made up of plain carbon steel 14C6. The lengths of the punches are properly quoted for the die performance. If the punches are having too much length, the compressive stress become excessive which results in tip breakage. The lengths of the punches are calculated from the Euler's formula. The critical force is calculated through one is fixed and other end set as free [7].

$$
F_{\text {cri }}=\frac{2 \pi^{2} E}{l^{2}} I_{\min }
$$

The length of the punches are calculated by

$$
\begin{aligned}
& I_{\max }=\sqrt{\frac{2 \pi^{2} E I_{\min }}{p}} \\
& I_{\min }=\frac{\pi D^{4}}{64} \\
& \mathrm{D}=\text { dia. of the punch }=7.5 \mathrm{~mm} \\
& I_{\min }=155 \mathrm{~mm}^{4} \\
& I_{\max }=149 \mathrm{~mm}
\end{aligned}
$$

This shows that the length of the punch which is safe and it can perform without failure.

\section{SIMULATIONXPRESS}

Simulation xpress is the tool to analyze the part of solid modeling in the solidworks. It provide the stress result with the design cycle. It helps to predict the part to perform under load. Whenever the problem arise related to analysis, need a comprehensive analysis of the product is required [8].

\subsection{Analysis of Punches}

The analysis of punches are analyzed by the simulation express tool in which each punch is made fixture at the top of the punch and the load is applied at the tip of punch. The maximum shear load is occurred in the edges of the punch and deformed to maximum deflection which is calculated. The following figures show that the punches are deformed only at the tip.

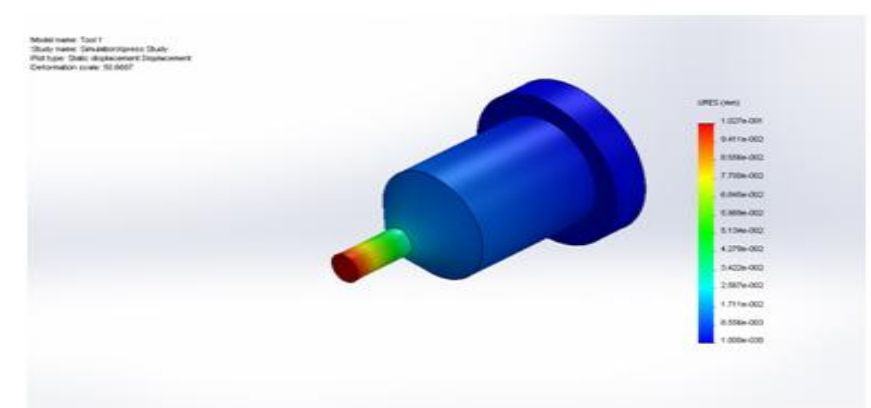

Fig - 3: Resultant displacement - Pierce punch

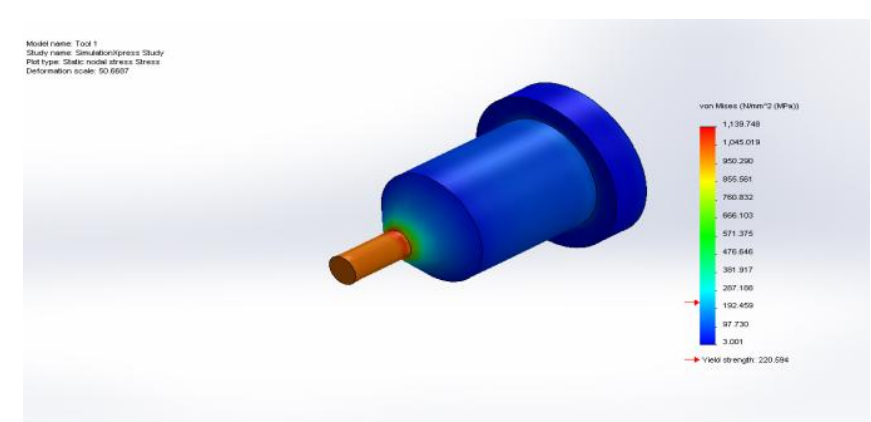

Fig - 4 Von mises - Pierce punch 


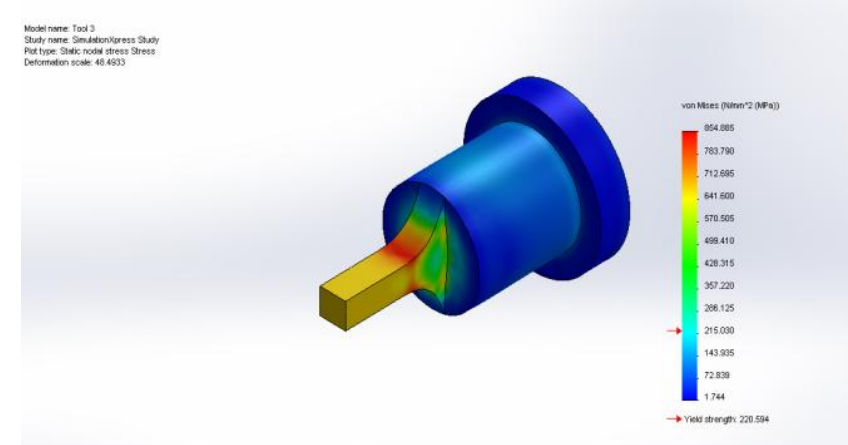

Fig - 5 Von mises stress - Blank punch

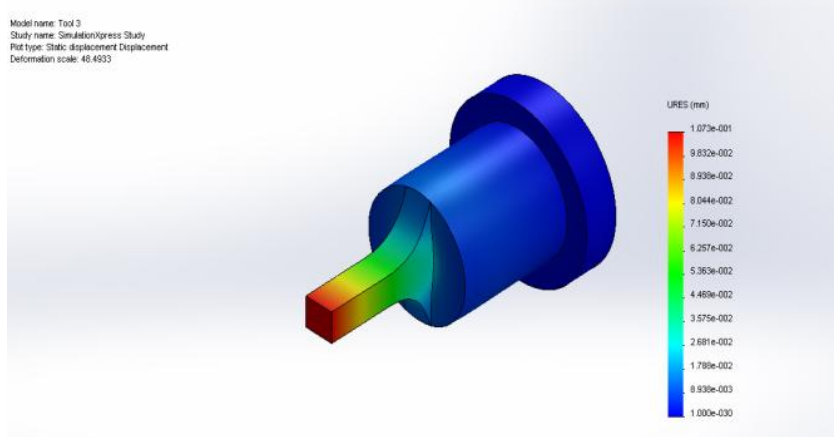

Fig - 6 Resultant displacement - Blank punch
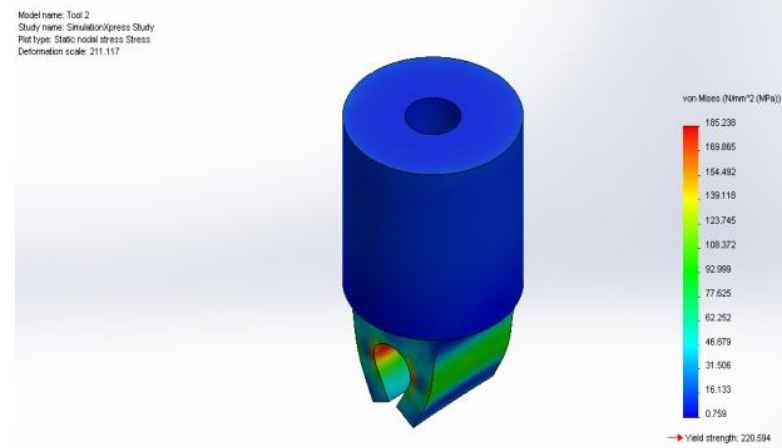

Fig - 7 Von mises stress - Bend form

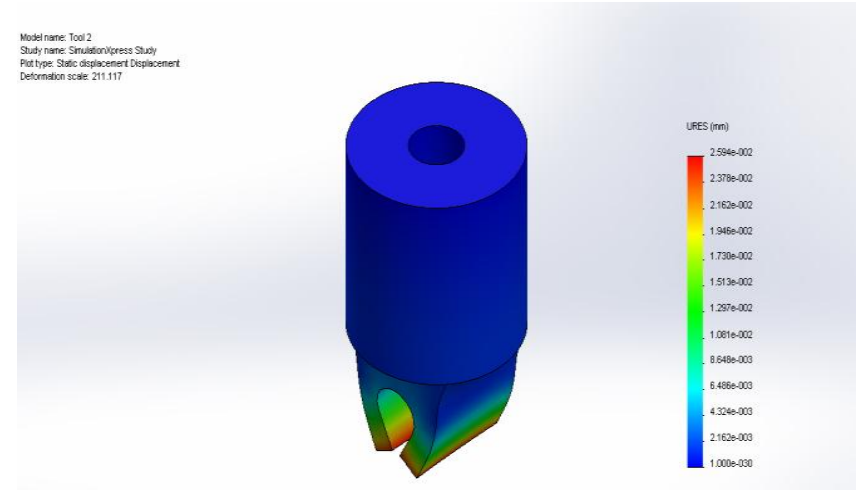

\subsection{Analysis of Guider Pin}

The guider pin is analyzed by the circumferential stress in the surface of the guider. The fixture is applied at the end of the guider surface in which the stripper plate is fixed. The maximum deformation is occurred in the intermediate of the fixture and the load applied.

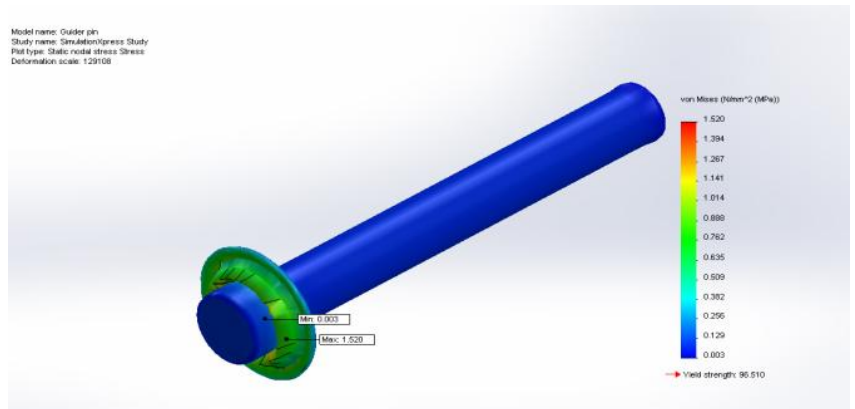

Fig - 9 Von mises stress - Guider pin

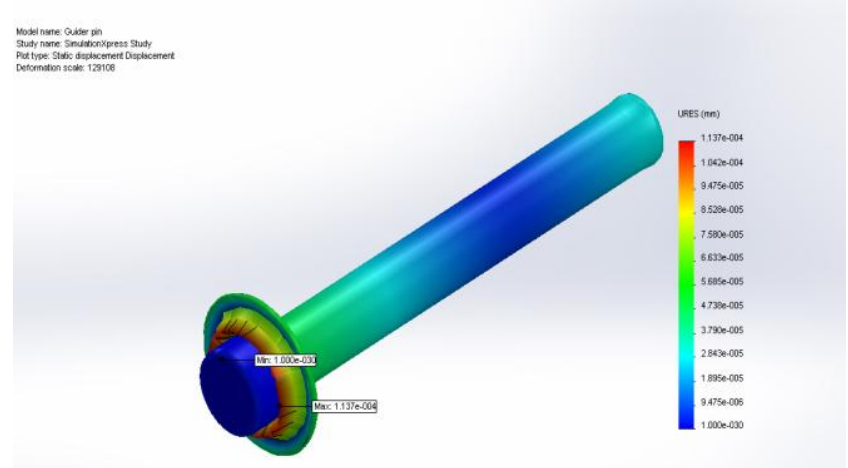

Fig - 10 Resultant displacement - Guider pin

\subsection{Die Block}

The analysis of die block is dominated by the punch force is applied on it. Hence, the punch force is applied in the surface of the die block and the fixture is placed at the other end of the die block. The maximum deflection is occurred at the punch is perforated.

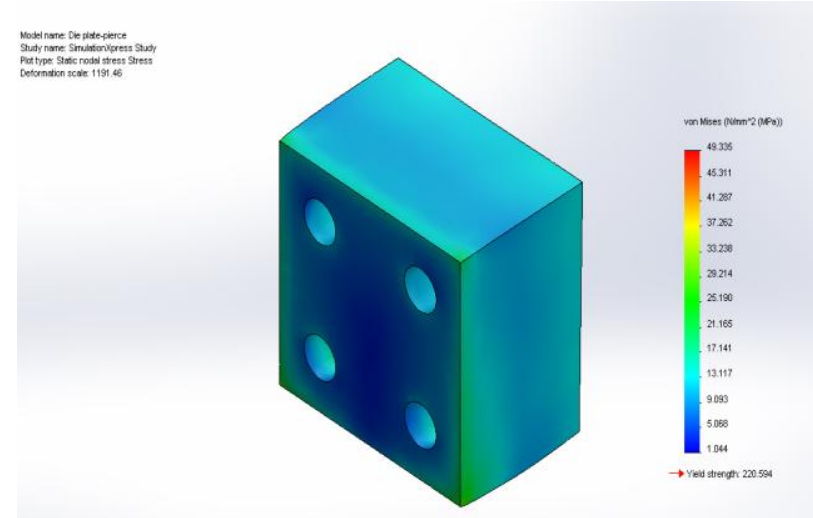

Fig - 11 Von mises stress - Die block

Fig - 8 Resultant displacement - Bend form 


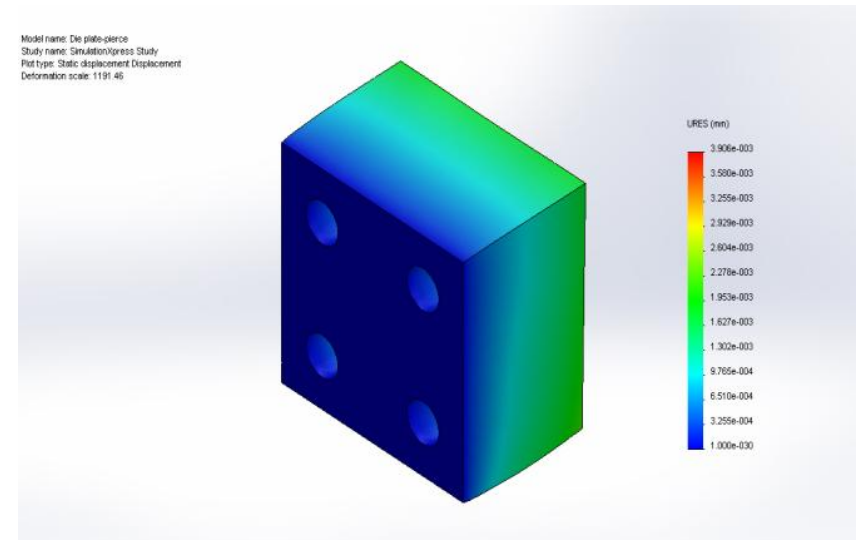

Fig - 12 Resultant displacement - Die block

\section{CONCLUSIONS}

This thesis is completely described about the punching die parts individually through analytical calculations and these parts are analyzed by the finite element methods with close meshing analysis. This die design specifically designed for the MSME industries which are facing the problems regarding their own criteria. By implementing this type of die design to compete few recommendations such as

- Increase of production rate/batch

- Get a possible product in a die

- Reduction of man power

- Eliminate the storage spaces for die.

\section{REFERENCES}

[1]. Ivana Suchy - Handbook of die design - McGraw Hill - New York - 2006

[2]. J.P. kaushish - Manufacturing processes - Hall of India Pvt Ltd - New Delhi - 2010

[3]. http://www.nortal.co.uk/LM6/

[4]. Alok nayar - The metals data book - McGraw Hill New Delhi - 1997

[5]. PSG college of technology - Design data Kalikathir Achchagam - India - 2013

[6]. Cyrll Donaldson - Tool design - McGraw Hill New York - 2008

[7]. R.K. Bansal - Strength of materials - Laxmi publications - New Delhi - 2014

[8]. V.S. Bhanjantri. Analysis of progressive dies. International journal of engineering and innovative technology (223): 2277 - 3754, 2014.

\section{BIOGRAPHIES}

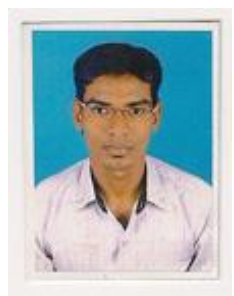

\section{AK. Kumaresh}

M.E - Engineering design

Sri Shakthi institute of engineering and technology. Coimbatore -62

India.

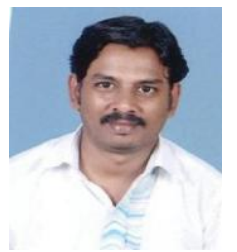

B. Balaji

Assistant professor

Sri Shakthi institute of engineering and technology. Coimbatore - 62

India.

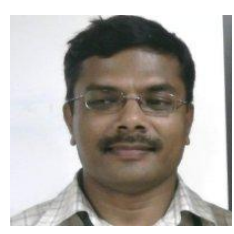

\section{Raj kumar}

Professor

Sri Shakthi institute of engineering and technology. Coimbatore -62

India. 